\title{
FINANCIAL LITERACY, MONEY ATTITUDE, DAN FINANCIAL MANAGEMENT BEHAVIOR GENERASI MILENIAL
}

\author{
Ida $^{1}$, Sri Zaniarti ${ }^{2}$, Graciela Ervina Wijaya ${ }^{3}$ \\ ${ }^{1}$ Program Studi Manajemen, Universitas Kristen Maranatha \\ Email: ida@eco.maranatha.edu \\ 2 Program Studi Manajemen, Universitas Kristen Maranatha \\ Email: sri.zaniarti@eco.maranatha.edu \\ ${ }^{3}$ Program Studi Manajemen, Universitas Kristen Maranatha \\ Email: gracielaervina81@gmail.com
}

\begin{abstract}
ABSTRAK
Perkembangan teknologi dan gaya hidup generasi milenial mendorong perilaku konsumtif sehingga pentingya mengetahui faktor- faktor yang memengaruhi financial management behavior generasi milenial agar tidak terjebak pada masalah keuangan. Penelitian ini mempunyai tujuan untuk menguji pengaruh financial literacy dan money attitude dari dimensi power prestige dan anxiety terhadap financial management behavior pada generasi millenial yang tinggal di Bandung. Teknik pengambilan sampel dengan metode sampling non-probability yaitu teknik purposive sampling. Sampel berjumlah 1.120 responden yang mayoritas adalah perempuan dan berpendidikan perguruan tinggi. Dari hasil pengujian menggunakan analisis regresi berganda menunjukkan financial literacy dan money attitude dari dimensi power prestige mempunyai pengaruh yang signifikan terhadap financial management behavior sedangkan money attitude-anxiety tidak mempunyai pengaruh terhadap financial management behavior pada generasi millenial yang tinggal di Bandung. Penelitian ini menyarankan peningkatan financial literacy dan money attitude- Power-prestige bagi generasi milenial, adanya kurikulum pendidikan mengenai literasi keuangan, dan bagi peneliti selanjutnya dapat melakukan penelitian bagi generasi milenial di luar kota Bandung serta meneliti faktor- faktor lain yang memengaruhi financial management behavior.
\end{abstract}

Kata Kunci: Generasi milenial, financial literacy, money attitude, financial management behavior

\begin{abstract}
Technological developments and the lifestyle of the millennial generation encourage consumptive behavior, so it is important to know the factoes that influence the financial management behavior of the millennial generation so that they are not trapped in financial problems. The purpose of this study was to empirically examine the effect of financial literacy and money attitude form the dimensions of power prestige and anxiety on financial management behavior in the millennial generation living in Bandung. This study uses a non-probability sampling method with a purposive sampling technique. The sample consisted of 1,120 respondents, the majority of whom were women and had university education. From the test results using multiple regression analysis shows that financial literacy and money attitude from the power prestige dimension have a significant effect on financial management behavior, while money attitude from the anxiety dimension has no effect on financial management behavior in the millennial generation who live in Bandung. in Bandung. This study suggests an increase in financial literacy and money attitude from the Power-prestige dimension for the millennial generation, the existence of an educational curriculum regarding financial literacy, and for further researchers to conduct research for millennials outside Bandung and examine other factors that influence financial management behavior.
\end{abstract}

Keywords: Millenial generation, financial literacy, money attitude, financial management behavior,.

\section{PENDAHULUAN}

\section{Latar Belakang}

Pola dan gaya hidup khususnya bagi generasi milenial banyak berubah dengan adanya perkembangan teknologi. Generasi milenial dikenal dekat dengan perkembangan teknologi, senang bergaul, berbagi pengalaman melalui media sosial, lebih suka menghabiskan uangnya untuk mendapatkan pengalaman dari pada menabung untuk menambah asset, lebih suka melakukan pembayaran non-cash, mudah bosan dengan barang yang dibelinya, suka hang out, makan- makan di cafe, maupun restoran, dan travelling sehingga perilaku konsumtif melekat 
pada generasi milenial. Perilaku konsumtif yang melekat pada generasi milenial dapat membuat mereka terjebak pada kesulitan keuangan.

Menurut Joo (2008) Financial Management behavior yang efektif dapat meningkatkan kesejahteraan finansial seseorang dan kegagalan pengelolaan keuangan pribadi dapat berakibat jangka panjang. Menurut Kholilah dan Iramani (2013) Financial Management Behavior adalah keinginan seseorang memenuhi kebutuhan hidupnya berdasarkan hasil usaha yang diperoleh. Dew dan Xiao (2011) membagi Financial management behavior dalam empat hal yaitu: Konsumsi, manajemen arus kas, tabungan, investasi, dan manajemen kredit. Faktor- faktor yang memengaruhi Financial Management behavior generasi milenial menjadi menarik untuk diteliti sehingga generasi milenial tidak terjebak pada kesulitan keuangan.

Dari beberapa hasil penelitian, terdapat faktor- faktor yang memengaruhi financial management behavior. Hasil penelitian Mien dan Thao (2015), Qamar, Khemta, \& Jamil (2016) menunjukkan bahwa financial literacy mempunyai pengaruh terhadap financial management behavior. Lusari \& Mitchell (2007) mengemukakan financial literacy sebagai pengetahuan bagi individu untuk mengelola keuangan yang baik agar mencapai kehidupan yang lebih sejahtera. Pengetahuan dan pemahaman pengelolaan keuangan pribadi diperlukan seseorang dalam pengambilan keputusan keuangan (Yushita, 2017). Lebih lanjut, Hailwood (2007) mengemukakan bahwa financial literacy seseorang akan memengaruhi bagaimana seseorang menabung, berhutang, melakukan investasi, dan mengatur keuangannya. Tanusdjaja (2018) juga mengemukakan bahwa status pendidikan seseorang menunjukkan seberapa besar financial literacy yang dimilikinya dan hasil penelitiannya menunjukkan bahwa pendidikan merupakan faktor yang sangat berpengaruh terhadap keputusan berinvestasi.

Selain faktor financial literacy, faktor money attitude juga memengaruhi financial management behavior berdasarkan hasil penelitian Qamar, Khemta, \& Jamil (2016), Syafitri dan Santi (2017) menunjukkan money attitude berpengaruh terhadap financial management behavior. Duravasula \& Lysonski (2007) mengemukakan bahwa sikap terhadap uang (money attitude) merupakan pemahaman dan sikap seseorang tentang arti dari uang sebagai bagian penting dalam hidup, sumber rasa hormat, kualitas hidup, kebebasan, dan bahkan untuk kejahatan. Perbedaan seseorang memahami dan menafsirkan peran uang dalam hidup yang tercermin dalam konsep money attitude seseorang. Gąsiorowska dan Helka (2012) juga mengemukakan bahwa perbedaan money attitude seseorang memiliki peranan penting yang berpengaruh terhadap sikapnya bekerja, gaya konsumsi, tabungan, hutang, investasi, dan persepsi mereka terhadap pendapatan.

Menurut Tang (1995) bahwa seseorang dapat mengganggap uang sebagai lambang kekuasaan dan prestise, kadang individu lain menganggap uang sebagai akar dari kejahatan. Yamuchi dan Templer (1982) membagi sikap terhadap uang dalam 5 dimensi yaitu: Power-prestige (kekuasangengsi), Retention time (keamanan - pengelolaan), Distrust (ketidakpercayaan), Quality (kualitas), dan Anxiety (kegelisahan). Sikap terhadap uang dari dimensi Power-prestige (kekuasan-gengsi), uang diartikan sebagai sumber kekuasaan, mendapatkan pengakuan eksternal, pencarian status, persaingan, dan pencapaian barang-barang mewah. Sikap terhadap uang dari dimensi Retention time (keamanan - pengelolaan) berarti uang harus dikelola dengan baik untuk masa depan, butuh perencanaan dan kehati-hatian dalam membelanjakan uang serta penggunaan yang berorientasi pada masa depan. 
Sikap terhadap uang dari dimensi Distrust (ketidakpercayaan) memiliki arti bahwa uang dapat menjadi sumber perilaku penuh curiga, memunculkan keraguan dalam situasi yang melibatkan penggunaan uang dan ketidakpercayaannya dalam mengambil keputusan penggunaan uang. Sikap terhadap uang dari dimensi Quality (kualitas) memberikan arti bahwa uang dapat menjadi simbol kualitas hidup dengan melakukan pembelian barang - barang yang berkualitas. Sedangkan sikap terhadap uang dari dimensi Anxiety (kegelisahan), uang digambarkan sebagai sumber kecemasan dan stres bagi pemiliknya (Yamuchi dan Templer,1982).

Lebih lanjut Gasiorowska (2015) juga menyatakan bahwa money attitude seseorang dari dimensi anxiety memiliki keyakinan bahwa uang sebagai sumber kekuatan dan juga akar kejahatan. Penelitian ini menggunakan faktor money attitude dari dimensi power-prestige dan anxiety karena generasi milenial dikenal sebagai generasi yang sering membagikan pengalaman mereka ke media sosial dan mudah bosan, maka perlu diteliti lebih lanjut money attitude generasi milineial dari dimensi power prestige dan anxiety.

Berdasarkan paparan di atas, maka penelitian ini bertujuan untuk menganalisis pengaruh financial literacy dan money attitude dari dimensi power prestige dan anxiety terhadap financial management behavior pada generasi millenial yang tinggal di Bandung. Generasi milenial yang ditinggal di Kota Bandung dijadikan sebagai responden karena menurut Reza (2020) Kota Bandung yang dikenal sebagai kota kembang dinilai menjadi kota favorit bagi kaum milenial karena memiliki lokasi untuk beriwisata, kulinernya yang enak dan lezat, dan memiliki udara yang sejuk.

\section{Rumusan Masalah}

Rumusan masalah pada penelitian ini adalah Apakah financial literacy, money attitude- power prestige, dan money attitude- anxiety berpengaruh signifikan terhadap financial management behavior pada generasi milenial yang tinggal di Kota Bandung?

\section{Pengembangan Hipotesis \\ Pengaruh Financial literacy terhadap financial management behavior}

Menurut Nababan dan Sadalia (2013) literasi keuangan dibutuhkan oleh individu agar dapat menikmati hidup dengan menggunakan sumber daya keuangannya dengan tepat dan dapat mencapai tujuan keuangan pribadinya. Hal ini juga diperkuat dengan pernyataan Margaretha dan Sari (2015) bahwa dengan literasi keuangan maka individu dapat memiliki kemampuan untuk membuat pertimbangan dan keputusan mengenai manajemen penggunaan uang sehingga individu tersebut dapat memperbaiki kesejahteraan hidupnya. Lebih lanjut, Laily (2013) menyatakan bahwa individu yang memiliki kemampuan untuk membuat keputusan yang benar tentang keuangan tidak akan memiliki masalah keuangan di masa depan dan menunjukkan perilaku keuangan yang sehat serta mampu menentukan prioritas kebutuhan bukan keinginan. Idris, et al (2013) menyatakan bahwa pentingnya financial literacy seseorang karena perbedaan financial literacy seseorang akan menentukan perbedaan perilaku suatu individu dalam hal tabungan, investasi, dan berhutang. Kaitan antara financial literacy dengan financial management behavior juga dapat dilihat dari beberapa hasil penelitian Mien dan Thao (2015), Qamar, Khemta, \& Jamil (2016) yang menunjukkan adanya pengaruh positif financial literacy terhadap financial management behavior. Dari uraian ini, maka hipotesis pertama penelitian ini adalah:

\section{H1: Financial literacy berpengaruh signifikan terhadap financial management behavior pada generasi milenial yang tinggal di Kota Bandung.}




\section{Pengaruh money attitude terhadap financial management behavior}

Sikap seseorang terhadap uang terbentuk dari pengalaman dan keadaan yang mereka alami selama hidup mereka sehingga uang dipersepsikan dapat memengaruhi perilaku seseorang (Qamar, Khemta, \& Jamil, 2016). Norvilitis, et al (2006) juga menyatakan bahwa eksplorasi mengenai money attitude seseorang dapat memberikan wawasan baru tentang bagaimana perilaku keuangan seseorang dalam hal mereka menabung, berhutang, menggunakan kartu kredit, dan melakukan pembelian kompulsif. Dari beberapa hasil penelitian seperti Wang (2009) terhadap pelanggan muda di Cina menemukan bahwa power prestige berpengaruh terhadap pembelian impulsif. Pembelian yang tidak direncanakan ini merupakan salah satu financial management behavior dari aspek konsumsi. Qamar, Khemta, \& Jamil (2016) juga menyatakan kecemasan terhadap uang untuk memperoleh kesejahteraan akan mempengaruhi financial practices seseorang. Hasil penelitian Qamar, Khemta, \& Jamil (2016), Syafitri dan Santi (2017) menunjukkan money attitude berpengaruh terhadap financial management behavior. Dari beberapa hasil penelitian- penelitian terdahulu mengenai money attitude dalam pengujiannya tidak membedakan money attitude dari dimensi power prestige dan anxiety. Penelitian ini mencoba menguji pengaruh money attitude dari dimensi power prestige dan anxiety terhadap financial management behavior. Dari uraian yang telah dijelaskan, maka Hipotesis kedua dan ketiga penelitian ini adalah:

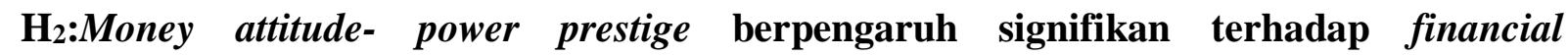
management behavior pada generasi milenial yang tinggal di Kota Bandung.

H3:Money attitude- anxiety berpengaruh signifikan terhadap financial management behavior pada generasi milenial yang tinggal di Kota Bandung.

Berdasarkan hipotesis di atas maka model penelitian ini adalah:

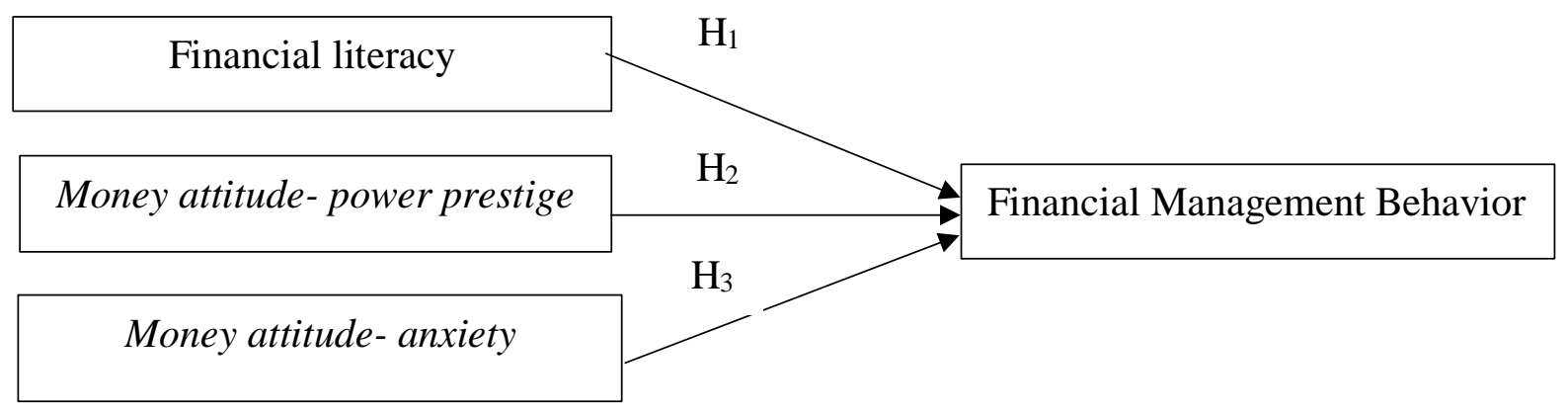

Gambar 1. Model Penelitian

\section{METODE PENELITIAN}

Penelitian ini menggunakan explanatory research dengan menjelaskan apakah terdapat pengaruh financial literacy, money attitude-power prestige, dan money attitude-anxiety terhadap financial management behavior. Teknik pengumpulan yang digunakan adalah survey dengan menyebarkan angket kepada generasi milenial yang lahir antara tahun 1980-2000 dan tinggal di Kota Bandung. Jumlah responden pada penelitian ini sebanyak 1.120 responden dengan mayoritas perempuan adalah sebanyak 591 (53\%). Hasil pengolahan data menunjukkan mayoritas responden pendidikan terakhirnya adalah Perguruan Tinggi yaitu sebesar 85\% (957 responden). Dalam penelitian ini pertanyaan- pertanyaan yang ada dalam kuesioner diadopsi dari penelitian-penelitian terdahulu dan jumlah item pertanyaan yang telah valid dan reliabel yang penjelasannya ada pada tabel 1 . 
Tabel 1. Indikator Pengukuran Variabel

\begin{tabular}{ccc}
\hline Variabel & item & Diadopsi dari \\
\hline Money Attitude-Power-prestige & 7 item & Yamuchi dan Templer (1982) \\
\hline Money Attitude-Anxiety & 6 item & Yamuchi dan Templer (1982) \\
\hline Financial Literacy & 7 item & Lusardi \& Mitchell (2007) \\
\hline Financial Management behavior & 4 item & Dew \& Xiao (2011); Perry \& Morris (2005) \\
\hline
\end{tabular}

Indikator-indikator dari variabel penelitian ini diukur dengan menggunakan skala Likert dari Angka 1 yang menyatakan sangat tidak setuju, angka 2 menyatakan tidak setuju, angka 3 menyatakan setuju, dan angka 4 yang menyatakan sangat setuju.

Pengujian validitas pada penelitian ini menggunakan korelasi bivariate dan instrumen penelitian yang digunakan telah valid karena skor korelasinya $\geq 0,5$ dan signifikan pada $\rho$ value 0,05 (Ghozali, 2006). Instrumen penelitian yang digunakan sudah reliabel dengan menggunakan nilai Cronbach's Alpha > 0.6 (Sekaran, 2003).

\section{HASIL DAN PEMBAHASAN}

Penelitian ini menggunakan analisis regresi linier berganda untuk menganalisis pengaruh Money Attitude-Power-prestige, Money Attitude -Anxiety, dan financial literacy terhadap financial management behavior generasi milenial. Hasil pengujian terdapat pada tabel 2:

Tabel 2. Hasil Pengujian

Sumber: Hasil Pengolahan SPSS

\begin{tabular}{cllcc}
\hline Hipotesis & Keterangan & sig & Keputusan \\
\hline $\mathrm{H}_{1}$ & $\begin{array}{l}\text { Money Attitude-Power-prestige } \\
\text { pengaruh terhadap financial management } \\
\text { behavior }\end{array}$ & .020 & diterima \\
\hline $\mathrm{H}_{2}$ & $\begin{array}{l}\text { Money Attitude-Anxiety mempunyai pengaruh } \\
\text { terhadap financial management behavior }\end{array}$ & .507 & ditolak \\
\hline $\mathrm{H}_{3}$ & $\begin{array}{l}\text { Financial Literacy mempunyai pengaruh terhadap } \\
\text { financial management behavior }\end{array}$ & .000 & diterima \\
\hline
\end{tabular}

Berdasarkan tabel 2 dapat dilihat bahwa hasil pengujian analisis regresi berganda menunjukkan bahwa Money Attitude - Power-prestige dan Financial Literacy mempunyai pengaruh signifikan terhadap financial management behavior sedangkan Money Attitude - Anxiety tidak mempunyai pengaruh signifikan terhadap financial management behavior.

Hasil penelitian menunjukkan bahwa Money Attitude - Power-prestige berpengaruh signifikan terhadap financial management behavior. Hal ini dapat dijelaskan bahwa generasi milenial dikenal sebagai generasi yang lebih mementingkan pengalaman dari pada kemewahan barang. Generasi milenial memandang kekayaan dengan menceritakan pengalaman daripada membeli barang yang mahal (Setiawan 2019). Hal ini mendukung hasil penelitian dari Qamar, Khemta, \& Jamil (2016), Syafitri dan Santi (2017)

Hasil penelitian menunjukklan bahwa Financial Literacy mempunyai pengaruh signifikan terhadap financial management behavior. Hal ini menunjukkan tingkat literasi keuangan yang semakin tinggi maka akan semakin baik dalam pengelolaan dan pengaturan keuangan. Hasil penelitian ini mendukung hasil penelitian Mien dan Thao (2015) dan Qamar, Khemta, \& Jamil (2016). 
Pengujian Money attitude dari segi anxiety pada generasi milenial tidak mempunyai pengaruh signifikan terhadap financial management behavior. Menurut Chrismonica (2019) generasi milenial tidak tahu nilai uang yang harus disimpan. Generasi milenial tidak memiliki kecemasan terhadap uang. Mereka memandang uang bukan satu-satunya cara dalam menyelesaikan masalah.

\section{KESIMPULAN DAN SARAN}

Kesimpulan dari hasil penelitian ini adalah Money Attitude-Power-prestige dan Financial Literacy mempunyai pengaruh yang signifikan terhadap financial management behaviour pada generasi milenial di kota Bandung sedangkan Money Attitude - Anxiety tidak mempunyai pengaruh yang signifikan terhadap financial management behaviour pada generasi milenial yang tinggal di kota Bandung dengan responden yang mayoritas adalah perempuan dengan pendidikan pada tingkat Perguruan Tinggi. Dari hasil penelitian ini, maka financial literacy dan money attitude dari dimensi sebagai Power-prestige sebagai faktor yang memengaruhi financial management behaviour generasi milenial di kota Bandung.

Saran dari hasil penelitian ini adalah perlunya meningkatkan financial literacy dan money attitude dari dimensi Power-prestige agar dapat meningkatkan financial management behaviour. Hasil penelitian ini diharapkan dapat memberikan masukan bagi dunia pendidikan dari segi kurikulum agar memasukkan kurikulum pembelajaran berupa literasi keuangan dan diberikan sejak dini di tingkat sekolah dasar. Bagi peneliti selanjutnya dapat melakukan penelitian bagi generasi milenial di luar kota Bandung dan juga meneliti faktor- faktor lain yang memengaruhi financial management behavior.

\section{Ucapan Terima Kasih}

Terima kasih kepada Universitas Kristen Maranatha yang telah membantu peneliti dalam hal pendanaan dan kepada responden yang telah membantu mengisi kuesioner pada penelitian ini sehingga penelitian ini dapat selesai.

\section{REFERENSI}

Chrismonica. (2019). Sebagian Besar Generasi Milenial Tak Tahu Nilai Uang yang Harus Disimpan. $\quad$ Retrieved $\quad$ November, $19 \quad 2019$, from https://www.liputan6.com/bisnis/read/4069489/sebagian-besar-generasi-milenial-taktahu-nilai-uang-yang-harus-disimpan

Dew, J., \& Xiao, J. (2011). The Financial Management Behavior Scale: Development and Validation. Journal of Financial Counseling and Planning, 22, 43-59.

Duravasula, S., \& Lysonski, S. (2007). Money attitudes, materialism, and achievement vanity: An investigation of young chinese consumers' perceptions. International Marketing Conference on Marketing \& Society, 6(1), 497-499.

Gasiorowska, A. (2015). The Impact of Money Attitudes on the Relationship Between Income and Financial Satisfaction. Polish Psychological Bulletin, 46(2), 197-208.

Gasiorowska, A., \& Helka, A. (2012). Psychological consequences of money and money attitudes in dictator game. Polish Psychological Bulletin, 43, 20-26. Doi: 10.2478/v10059-012-0003-8

Ghozali, I. (2006). Aplikasi Analisisi Multivariat Dengan Program SPSS. Edisi 3. Andi, Yogyakarta.

Hailwood, D. (2007). Financial Literacy and its Role in Promoting a Sound Financial System. Reserve Bank of New Zealand, 70(2), 37-47. 
Idris, F.H., Krishnan, K.S.D., Azmi, N. (2013). Relationship between financial literacy and financial distress among youths in Malaysia: An empirical study, Malaysian Journal of Society and Space, 9(4): 106 - 117.

Joo, S. (2008). Personal financial wellness. In J. J. Xiao (Ed.), Advances in consumer finance behavior research (pp. 21-33), Springer, New York.

Kholilah. N. A \& Iramani. R. (2013). Studi Financial Management Behavior pada Masyarakat Surabaya. Journal of Business and Banking, 3(1), 69-80. http://dx.doi.org/10.14414/jbb.v3i1.255

Laily. N. (2013). Pengaruh Literasi Keuangan terhadap Prilaku Mahasiswa dalam Mengelola Keuangan. Jurnal Pendidikan Akuntansi (JPA). 1(4). September 2013.

Lusardi, A \& Mitchell, O. (2007). Baby Boomer retirement security: The roles of planning, financial literacy, and housing wealth. Journal of Monetary Economics, 54, 205-224.

Margaretha. F. \& Sari. S. M. (2015). Faktor Penentu Tingkat Literasi Keuangan Para Pengguna Kartu Kredit di Indonesia. Jurnal Akuntansi \& Investasi. 16(2), 132- 144. Doi: 10.18196/jai.2015.0038.

Mien, N. \& Thao, T. (2015) Factors Affecting Personal Financial Management Behaviors: Evidence from Vietnam, Proceedings of the Second Asia-Pacific Conference on Global Business, Economics, Finance and Social Sciences (AP15Vietnam Conference.

Nababan. D. \& Sadalia. I. (2013). Analisis Personal Finance Literacy dan Financial Behavior Mahasiswa Strata I Fakultas Ekonomi Universitas Sumatera Utara. Jurnal Media Informasi Manajemen. 1(1).

Norvilitis, J. M., Merwin, M. M., Osberg, T. M., Roehling, P. V., Young, P., \& Kamas, M. M. (2006). Personality factors, money attitudes, financial knowledge, and credit-card debt in college students. Journal of Applied Social Psychology, 36(6), 1395-1413. https://doi.org/10.1111/j.0021-9029.2006.00065.x

Perry, V. \& Morris, M. (2005). Who Is in Control? The Role of Self-Perception, Knowledge, and Income in Explaining Consumer Financial Behavior. The Journal of Consumer Affairs, 39(2), 295-312. https://doi.org/10.1111/j.1745-6606.2005.00016.x

Qamar, M., Khemta, M., \& Jamil, H. (2016). How Knowledge and Financial Self-Efficacy Moderate the Relationship between Money Attitudes and Personal Financial Management Behavior. European Online Journal of Natural and Social Sciences, 5, 296308.

Reza (2020) Ini 3 Alasan bandung Diincar Banyak Generasi Milenial diakses di https://www.liputan6.com/lifestyle/read/4171926/ini-3-alasan-bandung-diincar-banyakgenerasi-milenial

Sekaran, U. (2003). Research Methods for Business: A Skill-Building Approach. Fourth Edition. John Wiley \& Sons, Inc, New York.

Syafitri, T.\& Santi, F. (2017) The Impact of Money Attitude on Personal Financial Management Behavior, and Self- Control as Moderation Variables. Journal of Personal Finances, $1(1), 1-11$.

Tang, T.L.P. (1995). The development of a short money ethic scale: attitudes toward money and pay satisfaction revisited. Personality and Individual Differences, 19, 809-816. https://doi.org/10.1016/S0191-8869(95)00133-6

Tanusjaja, H. (2018). Keputusan Investasi Investor Individu berdasarkan Kompetensi, Overconfidence, dan Pendidikan. Jurnal Muara Ilmu Ekonomi dan Bisnis. 2(1), 234244. doi: http://dx.doi.org/10.24912/jmieb.v2i1.998

Wang, A. (2009). Interplay of investors' financial knowledge and risk taking. The journal of behavioral finance, 10(4), 204-213 Doi: 10.1080/15427560903369292 
Yamuchi, K., \& Templer, D. (1982). The development of a money attitudes scale. Journal of Personality Assessment, 46: 522-528. https://doi.org/10.1207/s15327752jpa4605_14

Yushita. A. (2017). Pentingnya Literasi Keuangan bagi Pengelolaan Keuangan Pribadi. Jurnal Nominal. 6(1),11-26. https://doi.org/10.21831/nominal.v6i1.14330 